\title{
Política de ReconHeCiMENTo das DiferenÇas ÉTNICO-RACIAIS NO BRASIL: AÇÕES AFIRMATIVAS E A POLÍTICA PARA A EDUCAÇão SUPERIOR PÚblicA No GOVERNO LULA
}

\author{
Danilo de Souza Morais*
}

\section{Introdução}

Neste ensaio pretendo contribuir para a reflexão sobre as duas gestões do Governo Federal brasileiro sob a presidência de Luiz Inácio Lula da Silva, do PT (Partido dos Trabalhadores), a partir de análise da política de reconhecimento das diferenças. Detenho-me, no referido período, mais especificamente nas diferenças étnico-raciais, discutindo o quadro em que avançam as ações afirmativas nas universidades públicas, relacionando-as com as políticas do Governo Federal para a Educação Superior Pública.

As transformações na política de reconhecimento emergem com maior visibilidade na cena pública brasileira nos anos 2000, com a demanda pelo movimento social negro e a implementação, por iniciativa de governos estaduais e/ou por decisão de instituições públicas de Ensino Superior, de ações afirmativas que prevêem formas de acesso diferenciado - o que no debate público usualmente é definido como "cotas" -, para ingresso de estudantes negros/as nas universidades.

* Doutorando do Programa de Pós-Graduação em Sociologia da Universidade Federal de São Carlos (PPGS-UFSCar). Membro do Núcleo de Estudos Afro-brasileiros (Neab) e consultor do Programa de Ações Afirmativas (PAA), ambos também da UFSCar. É bolsista do CNPq. 
$\mid 82$ |

Política de reconhecimento das diferenças...

As ações afirmativas nas universidades públicas, indicativo da mudança no padrão de reconhecimento das diferenças étnicoraciais no Brasil, não são centralizadas por políticas do Governo Federal, porém ganham crescentes incentivos do mesmo. Assim sendo, apresentarei alguns dados gerais sobre estas iniciativas no país, para uma reflexão panorâmica sobre a mudança na política de reconhecimento que as ações afirmativas podem engendrar. Aqui se destacam os elementos de sinergia na relação entre as ações afirmativas desenvolvidas dentro da autonomia constitucional das universidades e o Governo Federal, no período entre 2003 e 2010.

\section{A abordagem do reconhecimento das diferenças \\ O conceito de reconhecimento, desde os trabalhos mais conhecidos de Charles Taylor e de Axel Honneth, além da polêmica entre este e Nancy Fraser, tem ganhado destaque crescente como instrumento de uma perspectiva válida para análises por meio das ciências sociais, possivelmente com maior influência sobre a sociologia. ${ }^{1}$ \\ Esta perspectiva, junto das interpretações feministas contemporâneas e dos estudos pós-coloniais ${ }^{2}$ podem ser identificadas de certa maneira como um campo de crítica e renovação das ciências sociais, que ainda carecem de um maior diálogo entre si.}

\footnotetext{
${ }^{1}$ Entre outras obras dos autores mencionados destaco os seguintes trabalhos: TAYLOR, C. Argumentos Filosóficos, RJ, Edições Loyola, 2000.; HONNETH, A. Luta por Reconhecimento: a gramática moral dos conflitos sociais, São Paulo, Ed. 34, 2003.; e FRASER, N. "Da Redistribuição ao Reconhecimento? Dilemas da Justiça na Era Pós-socialista", In: SOUZA, J. (org.) Democracia hoje: Novos desafios para a teoria democrática contemporânea Brasília, Ed. UNB, 2001.

${ }^{2}$ Ver a perspectiva em que faço um diálogo inicial entre estas teorias em MORAIS, D.S. "Estudos subalternos e a teoria gramsciana: diálogos e contribuições a uma sociologia política".In:Anais do XV Congresso Brasileiro de Sociologia, Curitiba, 2011.
} 
Não aprofundando o debate sobre as distinções teóricas entre os autores mencionados, apenas destaco, a partir de discussão desenvolvida em trabalho anterior ${ }^{3}$, que utilizo a noção de política de reconhecimento das diferenças próximo da acepção de Taylor, entretanto, não recorrendo e me limitando ao plano de referências do liberalismo, que é para o referido filósofo a fronteira normativa para o reconhecimento.

O campo mais amplo da política de reconhecimento das diferenças - sejam estas etárias/geracionais, raciais, étnicas, de gênero, sexuais - detém relevância, em um plano, para evidenciar a forma em que na dinâmica societal marcadores sociais de diferenças constituem grupos subalternos - LGBT, negros/as, mulheres, jovens -, como também a maneira que as políticas públicas, ou seja, a forma mais organizada do "Estado em ação", reconhece tais diferenças. Neste segundo aspecto um breve olhar, mesmo que panorâmico, das duas gestões do Presidente Lula apontam uma ampliação e mudança na política de reconhecimento no país. Alguns exemplos são a criação de organismos específicos, no Executivo Federal, para políticas com este perfil, tais como: Secretaria Especial de Políticas de Promoção da Igualdade Racial (SEPPIR), a Secretaria de Políticas para as Mulheres (SPM), a Secretaria Nacional de Juventude $(\mathrm{SNJ})^{4}$, dentre outros.

\footnotetext{
${ }^{3}$ Ver MORAIS, D. S. "A disputa pela construção da cidadania no Brasil e o reconhecimento das diferenças". In Anais do XIV Congresso Brasileiro de Sociologia, Rio de Janeiro, 2009.

${ }^{4}$ SEPPIR e SPM foram instituídas em 2003. A SNJ, instituída em 2005, mantém-se desde sua criação vinculada à Secretaria-Geral da Presidência da República. O histórico destes organismos do Executivo Federal, criados na gestão de Lula, foram encontrados em www.balancodegoverno.presidencia.gov.br - consultado em 30 de setembro de 2011. No sítio eletrônico mencionado está disponível o balanço oficial de governo do período 2003-2010.
} 
| 84 |

Política de reconhecimento das diferenças...

Outro importante exemplo a indicar mudanças na política de reconhecimento é percebido na maior permeabilidade do Executivo Federal para interlocução com segmentos e temas subalternizados na vida social e na relação com a política institucional brasileiras, o que ocorre pelo estabelecimento de novos Conselhos Setoriais e Gestores de Políticas Públicas, além da realização de um número bastante significativo de novas Conferências Setoriais. ${ }^{5}$

Deve-se chamar a atenção, entretanto, que há diferenças entre as diferenças. Em outras palavras, de um lado, na dinâmica societal existem especificidades na forma como distintos marcadores sociais de diferenças são instrumentalizados como forma de subalternização dos grupos sociais, bem como na forma como tais grupos se valem de identificações subalternas para organizarem sua ação política - por exemplo: o machismo e o sexismo operam de maneira distinta do racismo; e o movimento feminista tem um histórico e uma dinâmica, distintos do histórico e da dinâmica do movimento social negro. De outro lado, para construção de políticas públicas, nas ações dos atores do Estado, a política de reconhecimento também guarda especificidade na relação com os diferentes grupos subalternos.

Numa análise de maior complexidade e amplitude, na perspectiva dos estudos subalternos buscar-se-ia compreender como estas especificidades, entre as diferenças, convergem na construção e manutenção de toda a ordem social. Mesmo concordando com este ponto de vista geral, como já explicitei em trabalho anterior, ${ }^{6}$ me limito aqui à análise de como a política de

\footnotetext{
${ }^{5}$ Entre 1988 e 2009 foram realizadas Conferências Nacionais em 33 diferentes temas. Dentre estes temas 22 foram introduzidos nos primeiros 7 anos do governo do Presidente Lula. Ver POGREBINSCHI, T. \& SANTOS, F. "Contra a falácia da crise institucional: Conferências Nacionais de políticas públicas e o impacto (positivo) sobre o Congresso". Rev. Eletrônica Insight/Inteligência. Abril-Maio-Junho de 2010. Disponível em http://www.insightnet.com.br/inteligencia/49/PDFs/08.pdf - acessado em 30 de setembro de 2011.
}

${ }^{6}$ MORAIS, D. S. Op. Cit. 2011. 
reconhecimento das diferenças étnico-raciais fundamenta nossa ordem social e de como, portanto, mudanças na política de reconhecimento podem indicar transformações também de sua hegemonia.

\section{Contextualizando a política de reconhecimento das diferenças étnico-raciais no Brasil e sua atual transformação}

No início da década de 1930, com o governo Getúlio Vargas, um projeto político de modernização conservadora no Brasil inicia sua hegemonia. Tal hegemonia se mantém, apesar das distinções e até do antagonismo interno, até meados dos anos 1980, quando inicia o fim do regime autoritário instalado em 1964 e a transição para o regime democrático. Um dos construtos do projeto político em questão é o próprio moderno Estado-nacional no país, fundamentado ideologicamente em uma pretensa união harmônica das "três raças" (indígenas, negros e brancos), ou seja, baseado no mito da democracia racial brasileira.

Em linhas gerais o projeto de modernização conservadora - tomado por alguns, como Luiz Werneck Vianna, como sinônimo de nacional-desenvolvimentismo ${ }^{7}$-, além de auxiliar decisivamente na constituição da ideologia da democracia racial no Brasil, pode ser caracterizado pela centralização no Estado como indutor do desenvolvimento econômico, regulador do mercado e majoritariamente repressivo e/ou tutelar na relação com a sociedade civil. Desenvolvido principalmente em períodos político-autoritários a partir da era Vargas, o projeto de modernização conservadora tem, evidentemente, atores mais progressistas, como no caso de Vargas, e os mais reacionários, caso do regime autoritário de 1964-1985.

${ }^{7}$ Ver VIANNA, L. J. W. A viagem (quase) redonda do PT. Jornal de Resenhas, p. 12 - 14, 05 jul. 2009; e PEZZONIA, R. ; SZWAKO, J. ; VIANNA, L. J. W. . Vida Intelectual Vida Política (entrevista). Idéias (UNICAMP), v. 1, p. 173-195, 2010. 
$\mid 86$ |

Política de reconhecimento das diferenças...

Especialmente desde o fim da $2^{\text {a }}$ Grande Guerra, portanto, a democracia racial respondeu pela necessária manutenção do consenso/consentimento - de tipo passivo, em que pese a contribuição de setores importantes da intelectualidade negra para sua construção - para a hegemonia da modernização conservadora no Brasil, compondo o quadro de nossa cidadania regulada ${ }^{8}$ ou a formação dominante da cidadania.

Concordando com Antônio Sergio Alfredo Guimarães, entende-se que o mito da democracia racial, mesmo como formação ideológica do racismo em nossa sociedade, foi também a partir deste período um "compromisso político e social do moderno Estado republicano brasileiro" ${ }^{\prime}$, que orienta a ação estatal para uma integração subordinada da população negra. Assim queremos ressaltar que a cidadania dominante não só é uma forma de estratificação pelo mundo do trabalho através da ocupação, como na definição de Wanderley Guilherme dos Santos, mas também pela origem étnico-racial ou pela forma como as pessoas são identificadas socialmente por sua cor ou raça.

Em outras palavras, podemos interpretar que mais do que um constructo cultural, a democracia racial na acepção de Guimarães, é também um constructo político para a integração limitada ou subalterna da população negra ${ }^{10}$, o que não deixa de ser uma forma de politica de reconhecimento.

Já na resistência ao regime autoritário de 1964-1985 nasce a contestação da democracia racial como política de reconhecimento, identificada crescentemente pelos militantes do movimento social negro, que se re-organiza em fins da década de 1970, como uma ideologia, no sentido de uma "falsa consciência", que encobriria o racismo realmente existente na sociedade brasileira. Neste sentido, e como um exemplo da re-emergência dos movimentos

${ }^{8}$ SANTOS, W.G. Cidadania e Justiça, Rio de Janeiro, Ed. Campus, 1978.

${ }^{9}$ GUIMARÃES, A. S. A. Classes, raças e democracia, São Paulo, Ed. 34, 2002. p. 110.

${ }^{10}$ GUIMARÃES, A. S. A. "Depois da democracia racial”, Rev. Tempo Social, São Paulo, v. 18, n. , 2, p. 269-297, Nov. 2006. 
sociais no período de democratização político-institucional do país há a formação do Movimento Negro Unificado (MNU).

Nascido em 1978 e primeiramente denominado Movimento Negro Unificado Contra a Discriminação Racial, o MNU explicita em seu discurso uma relação de continuidade para com organizações que o precederam no movimento social negro, como a Frente Negra Brasileira (FNB), da década de 1930, e o Teatro Experimental do Negro (TEN), de fins dos anos de 1940 e início dos 1950. Entretanto, o MNU guarda importante distinção em relação a estas organizações anteriores, por combinar, segundo Antônio Sérgio A. Guimarães “(...) três movimentos em um: a luta contra o preconceito racial; a luta pelos direitos culturais da minoria afro-brasileira; a luta contra o modo como os negros foram definidos e incluídos na nacionalidade brasileira." ${ }^{11}$, ou seja, se opõe ao compromisso político-cultural que representa a democracia racial.

Em síntese, remetendo à interpretação de Florestan Fernandes, Guimarães ressalta que neste momento de re-emergência do movimento negro, nos anos de 1970 e nos anos 1980, o novo é “(...) a demanda por direito à diferença cultural pari passu à demanda por direitos sociais e respeito pelos direitos civis dos negros." 12 Este nos parece um dos indicativos fundamentais para relacionar uma nova política do reconhecimento das diferenças, não dissociada, como vemos, de políticas consideradas de redistribuição. Porém, Antonio S. Alfredo Guimarães parece interpretar diferentemente este processo, pois, para ele, o que vem substituindo a hegemonia da democracia racial no Brasil, e também seus congêneres em outros Estadosnacionais da América Latina que saíram de regimes autoritários nas décadas de 1980 e 1990, seria um multiculturalismo necessariamente associado ao neoliberalismo.

A questão central para Guimarães é que uma "ideologia multiculturalista", como parte da hegemonia neoliberal, estaria

${ }^{11}$ GUIMARAES, A. S. A. Op. Cit., 2002. p. 160.

${ }^{12}$ GUIMARAES, Op. Cit, 2002. p. 159. 
188 |

Política de reconhecimento das diferenças...

substituindo o ideário da democracia racial, parte da modernização conservadora. Portanto, a erosão da democracia racial no país não significaria, necessariamente, a superação das desigualdades que se apresentam em termos raciais, antes disso, pode reproduzir estas desigualdades em outros termos, sem modificar suas bases. Assim é que o autor avalia o governo Lula, pelo que denomino política de reconhecimento das diferenças étnico-raciais.

Certamente da erosão da democracia racial como política de reconhecimento no Brasil, não necessariamente deriva a superação da desigualdade racial, muito menos a condição mais ampla de subalternização dos não-brancos, principalmente negros e indígenas. Porém, a substituição desta por um "multiculturalismo neoliberal" parece mais uma aposta interpretativa do autor, num quadro que de fato ainda está em disputa. O problema é que Guimarães parte do pressuposto que a "era Lula" se caracteriza apenas pelo neoliberalismo e, assim, a conclusão de que a nova política de reconhecimento deva se adequar a este projeto parece óbvia.

Francisco de Oliveira e Carlos Nelson Coutinho ${ }^{13}$, cada um ao seu modo, cometem o mesmo equívoco que Guimarães, pois encaram o governo Lula como mera continuidade ou mesmo aprofundamento do projeto neoliberal. Vianna parece ter encontrado uma chave importante, diferente destes autores, ao retomar o tema da revolução passiva ${ }^{14}$. Todavia, se levamos em consideração de fato as categorias gramscianas para pensar

${ }^{13}$ Ver em Oliveira a noção de "hegemonia às avessas" e em Coutinho a noção de "hegemonia da pequena política" in OLIVEIRA, F., Braga, R. \& RIZEK, C. S. (Orgs.). Hegemonia às Avessas. 1. ed. São Paulo: Boitempo Editorial, 2010.

${ }^{14} \mathrm{Na}$ revolução passiva, para Gramsci, os elementos de renovação se sobrepõem à também operante restauração, ou seja, podem ser constituídos inclusive novos direitos para os grupos subalternos, porém os mesmos são uma concessão "pelo alto". Para a diferenciação entre as categorias de revolução passiva, contra-reforma (onde os elementos regressivos são mais explícitos) e reforma intelectual e 
a revolução passiva, coloca-se a pergunta: em que termos se está colocando a construção do consenso/consentimento, ou seja, o pilar fundamental da hegemonia? Se as novas e/ou ampliadas formas de participação da cidadania nos assuntos públicos não forem encaradas apenas sob a ótica do transformismo, mas sim sob a possibilidade de partilha efetiva do poder ${ }^{15}$ de decisão, certamente a articulação da interpretação de Vianna - que ressalta a retomada da iniciativa do Estado-nacional - e Guimarães - que ressalta a erosão da democracia racial como compromisso políticocultural -, pode ensejar um entendimento bastante distinto da "era Lula", a partir da abordagem da política de reconhecimento das diferenças étnico-raciais.

As ações afirmativas nas universidades públicas são um grande exemplo para meu argumento, pois entram na chave de parte das demandas históricas do movimento social negro no Brasil, que re-emergiu em fins da década de 1970 com o MNU.

Ações Afirmativas em Universidades Públicas no Brasil e as políticas para Educação Superior Pública no Governo Lula

O tema da educação é central nas preocupações, demandas e propostas do movimento negro em toda sua história no século XX. Petronilha Beatriz Gonçalves e Silva e Luiz Alberto

moral (elementos de renovação mais explícitos) ver GRAMSCI, A. Cadernos do Cárcere. Volume 4. Rio de Janeiro: Civilização Brasileira, 2001. ${ }^{15}$ Forma de participação inserida na concepção de um projeto político democrático-participativo, em oposição à concepção de participação do projeto neoliberal. Para estas diferenciações ver DAGNINO, E. "Sociedade civil, participação e cidadania: de que estamos falando?", In: Mato, D. (coord.) Políticas de ciudadanía y sociedad civil en tiempos de globalización. Caracas, FACES, Universidad Central de Venezuela, 2004. Em abordagem distinta, mas que enfatiza o elemento de experimentalismo democrático, portanto, analisando de forma positiva a significativa inclusão de novas agendas e atores no governo Lula ver POGREBINSCHI, T. \& SANTOS, F. Op. Cit. 2010. 
|90|

Política de reconhecimento das diferenças...

O. Gonçalves ${ }^{16}$ descrevem estas demandas, desmistificando certo senso comum que acusa o movimento negro no Brasil de apenas discutir o tema da educação quando este está relacionado à demanda mais recente por "cotas" no Ensino Superior. Já Tatiane C. Rodrigues desmistifica a noção equivocada de que não houve legislação abertamente racista no Brasil após o encerramento formal da escravização de pessoas negras e a institucionalização da República, ressaltando como esta legislação racista afetava diretamente as políticas públicas de educação. ${ }^{17}$

O conteúdo acima é importante para demonstrar a dimensão do processo histórico, de lutas sociais e políticas no Brasil, que possibilitou trazer à cena pública do país com tanta ênfase a partir da segunda metade da década de 1990 e mais ainda nos anos 2000 a discussão das desigualdades raciais na educação e em outras áreas das políticas públicas, assim como as medidas para superar estas desigualdades ${ }^{18}$. Desta forma contraria-se a ênfase da abordagem de Guimarães, em que a nova política de reconhecimento das diferenças étnico-raciais, que substitui a democracia racial, estaria necessariamente vinculada a um "multiculturalismo neoliberal" presente no "mercado internacional de ideias".

${ }^{16}$ GONÇALVES, L.A.O. \& SILVA, P. B.G. "Movimento Negro e Educação". Rev. Brasileira de Educação, Nov.-Dez., n. 015, ANPED, São Paulo, 2000. pp. 134-158.

${ }^{17}$ Segundo a autora a Constituição de 1934, por exemplo, nos artigos 121 e 138, “(...) ao mesmo tempo em que repudia a discriminação racial, prescreve a eugenia no sistema educacional e restrições étnicas na escolha dos imigrantes" RODRIGUES, T.C. "Movimento negro e o direito à diferença", In ABRAMOWICZ, A., BARBOSA, L. M. \& SILVÉRIO, V. R. (orgs), Educação como prática da diferença, Campinas, Ed. Autores Associados, 2006. p.111.

${ }^{18}$ Ver dados oficiais do IBGE (Instituto Brasileiro de Geografia e Estatística) em IBGE. Síntese dos Indicadores Sociais: uma análise das condições de vida da população brasileira, Rio de Janeiro, IBGE, 2010 - a especificidade e persistência da desigualdade racial, especialmente as desvantagens 
Alguns dos marcos institucionais no Brasil que são em grande parte produto deste histórico de lutas sociais e que possibilitam crescentemente mudanças na política de reconhecimento, buscando a superação das desigualdades raciais na educação são: a Constituição de 1988; a Lei de Diretrizes e Bases da Educação (LDB) de 1996 (Lei no 9.394/96); a Lei 10.639 de $2003^{19}$; o parecer do Conselho Nacional de Educação (CNE/ CP03 de 2004) que regulamenta esta modificação da LDB e institui as Diretrizes Curriculares Nacionais para a Educação das Relações Étnico-Raciais e para o Estudo da História e Cultura da África e dos Afro-Brasileiros; e as primeiras iniciativas de ações afirmativas no Ensino Superior, com recorte racial para negros/as, no início dos anos 2000.

É importante salientar que por ação afirmativa deve-se entender todo o tipo de discriminação positiva voltada a segmentos reiteradamente marginalizados em determinada ordem social. Como políticas públicas podem ser definidas como: medidas especiais e temporárias, tomadas pelo Estado (...) com o objetivo de eliminar desigualdades historicamente acumuladas, garantindo a igualdade de oportunidade e tratamento, bem como de compensar perdas provocadas pela discriminação

da população negra (pretos e pardos) em comparação com a população branca. Ver também IPEA (Instituto de Pesquisa Econômica Aplicada), órgão oficial que da mesma forma tem corroborado a persistência dos dados sobre desigualdades raciais no Brasil, como em THEODORO, M. (org.) As políticas públicas e a desigualdade racial no Brasil: 120 anos após a abolição. Brasília, Ipea, 2008. Das pesquisas referenciais sobre as desigualdades raciais no Brasil destaco HASENBALG, C. Discriminação e Desigualdades Raciais no Brasil. Belo Horizonte, Ed. UFMG, 2005.

${ }^{19}$ Altera a LDB e torna obrigatório o estudo da História e Cultura da África e dos Afro-brasileiros em todos os níveis de ensino do país. Posteriormente é complementada pela Lei no 11.645 de 2008, que torna obrigatório também o ensino da História e Culturas dos Povos Indígenas no Brasil. 
192 |

Política de reconhecimento das diferenças...

e marginalização, por motivos raciais, étnicos, religiosos, de gênero e outros ${ }^{20}$

As ações afirmativas no Ensino Superior Público no Brasil, demandadas pelo movimento negro e que, portanto, adotam diferentes mecanismos para possibilitar maiores condições de acesso a este nível de ensino para esta população, passam a ser uma realidade a partir das experiências de cotas para negros nos cursos de graduação da UNEB (Universidade do Estado da Bahia), da UERJ (Universidade do Estado do Rio de Janeiro), da UENF (Universidade Estadual do Norte Fluminense) e da UnB (Universidade de Brasília), implementadas desde o ano de $2003 .^{21}$

Em poucos anos, de 2003 a 2009, das 90 Instituições Públicas de Ensino Superior brasileiras, a pesquisa de João Feres Júnior aponta que 57, dentre estas 28 Instituições Federais, haviam instituído alguma forma de ação afirmativa para ingresso em seus cursos de graduação. ${ }^{22}$ Mesmo enfrentando forte oposição de praticamente todas as grandes empresas de mídia no Brasil e de parcela dos intelectuais acadêmicos - como também descreve Feres Júnior - verifica-se que é muito significativo o número destas experiências e sua expansão pelo país nesta primeira década do século XXI.

Segundo Valter Roberto Silvério e Sabrina Moehlecke, a partir da gestão iniciada em 2003 no Governo Federal, sob a presidência de Lula é que "as ações afirmativas passam a ser assumidas pelo governo brasileiro de maneira mais sistemática e institucional, sendo inclusive consideradas no desenho de suas

${ }^{20}$ Grupo de Trabalho Interministerial para a Valorização da População Negra - Ministério da Justiça, 1996, p. 10.

${ }^{21}$ Nos casos da UENF e UERJ estas iniciativas foram implementadas por força de lei estadual - Lei $\mathrm{n}^{\text {}}$ 3.708/2001. Já para os casos da UnB e UNEB, as ações afirmativas foram uma decisão do Conselho Universitário de cada uma destas instituições.

${ }^{22}$ FERES JÚNIOR, J. "Ação Afirmativa: Política Pública e Opinião", Rev. Sinais Sociais, RIO DE JANEIRO 38, v. 3 n. 8, p. 38-77, setembrodezembro 2008, p. 41. 
secretarias e ministérios" 23 - a SEPPIR e a SECAD (Secretaria de Educação Continuada, Alfabetização e Diversidade), esta última no âmbito do Ministério da Educação (MEC), são exemplares na análise de Silvério e Moehlecke.

É fato que as iniciativas para a implementação de ações afirmativas nas universidades públicas, no que diz respeito às Instituições Federais de Ensino Superior (IFES), desde sua primeira experiência com a UnB, são tomadas dentro da chamada autonomia universitária. Desta maneira foram decisões das próprias instituições, não centralizadas por uma política dirigida especificamente a este fim pelo Governo Federal. Todavia, no período entre 2003 e 2010, medidas significativas foram tomadas pelo Governo Federal no campo da Educação Superior Pública e minha hipótese é que estas medidas, em geral, podem ter impactado positivamente na adoção das ações afirmativas pelas IFES. Por esta razão, faço a partir daqui considerações sobre algumas destas iniciativas do Executivo Federal, com a pretensão apenas de uma reflexão bastante inicial, guiado pela hipótese proposta.

Um primeiro exemplo de política federal é o programa Uniafro (Programa de Ações Afirmativas para a População Negra nas Instituições Federais e Estaduais de Educação Superior), que estabeleceu parcerias entre Ministério da Educação (MEC)/ SECAD e as universidades públicas, principalmente a partir de propostas desenvolvidas por Núcleos de Estudos Afro-brasileiros (NEABs) provenientes das instituições ${ }^{24}$. O programa consistia, em seu formato entre os anos de 2008 e 2010, em financiamento por parte do MEC/SECAD a ações para formação continuada de professores da Educação Básica e a elaboração de material didático, com o objetivo de implementação da Lei no 10.639/03.

${ }^{23}$ SILVÉRIO, V. R. \& MOEHLECKE, S. Ações Afirmativas nas Políticas Educacionais: o contexto pós-Durban. São Carlos, EdUFSCar, 2009 p. 11.

${ }^{24}$ Informações sobre o Programa Uniafro foram colhidas do sítio eletrônico do MEC, no link http://portal.mec.gov.br/ ndex.php?Itemid=86\&id=12260\&option=com_content\&view=article consultado em 30 de setembro de 2011. 
|94 |

Política de reconhecimento das diferenças...

O Uniafro, sob um primeiro olhar, pode parecer não influir tão diretamente em políticas afirmativas para o acesso nos cursos de graduação das instituições. Deve-se considerar, porém, que ao fortalecer nas universidades públicas os NEABs - núcleos de estudos envolvidos em atividades de ensino, pesquisa e extensão, em que professores e estudantes de diferentes áreas trabalham com variadas temáticas, mas a partir do eixo das relações étnico-raciais -, intelectuais acadêmicos negros/as e/ou anti-racistas deles participantes podem ter conseguido mais instrumentos para a intervenção na política acadêmica em suas universidades, contribuindo diretamente para a construção, adoção e implementação de políticas afirmativas para acesso e permanência.

Outra ação do Governo Federal, o Plano Nacional de Assistência Estudantil (PNAES), não carece de maior explicação sobre a relação com a adoção de políticas afirmativas, dada a necessidade de que para qualquer iniciativa de democratização de acesso de estudantes serem imprescindíveis também políticas de apoio material a sua permanência. O PNAES passou a garantir um orçamento específico voltado à assistência estudantil para execução das IFES, que podem utilizar o recurso para atender seus estudantes a partir de critérios sócio-econômicos, portanto, voltados a estudantes considerados de famílias de baixa renda. Implementado desde 2008 o PNAES teve novo decreto em 2010, onde se destacam as seguintes áreas em que as IFES podem apoiar estudantes: moradia estudantil; alimentação; transporte; atenção à saúde; inclusão digital; cultura; esporte; creche; apoio pedagógico; atenção às pessoas com deficiência e pessoas com super dotação. ${ }^{25}$

25 Decreto n. 7.234, de 19 de julho de 2010, disponível no sítio http://www.planalto.gov.br/ccivil_03/_Ato2007-2010/2010/Decreto/ D7234.htm - consultado em 30 de setembro de 2011. Desde sua implementação em 2008 até o ano de 2010 foram investidos no PNAES 633,1 milhões de reais em recursos federais - dados oficiais disponíveis no sítio eletrônico www.balancodegoverno.presidencia.gov.br, consultado em 30 de setembro de 2011. 
Também na chave da preocupação com maiores condições de permanência, pela garantia de mais recursos materiais, como também para o desenvolvimento acadêmico de estudantes que ingressam por ações afirmativas nas IFES, o Governo Federal por iniciativa conjunta de CNPq/ MCT (Conselho Nacional de Desenvolvimento Científico e Tecnológico do Ministério da Ciência e Tecnologia) e SEPPIR - estabeleceu uma nova modalidade de bolsas de Iniciação Científica (IC) para as universidades com políticas afirmativas e que possuem cotas do Programa Institucional de Bolsas de Iniciação Científica (PIBIC), denominada PIBIC nas Ações Afirmativas (PIBIC-Af). Excetuando a especificidade de ser exclusiva para ingressantes por formas de acesso diferenciado por ações afirmativas, o PIBIC-Af é criado em 2009 com os mesmos objetivos do PIBIC, pois é voltado para o apoio, com concessão de bolsas, ao desenvolvimento acadêmico por meio da IC a estudantes de graduação, que devem estar sob a orientação de professor/a responsável. ${ }^{26}$

Entre todas as iniciativas do governo Lula voltadas à Educação Superior Pública, certamente as de maior impacto foram o Programa de Expansão das IFES e o Programa de Apoio a Planos de Reestruturação e Expansão das Universidades Federais (REUNI). ${ }^{27}$ É bastante razoável supor que um quadro geral de

${ }^{26}$ As bolsas PIBIC-Af têm vigência de 12 meses e o valor mensal de $\mathrm{R} \$ 360,00$, seguindo assim os mesmos parâmetros das demais bolsas PIBIC. Informações sobre o PIBIC-Af foram colhidas do sítio eletrônico do CNPq, no link http://cnpq.br/programas/pibic_afirm/faq.htm consultado em 30 de setembro de 2011.

${ }^{27}$ Entre 2003 e 2010 a implantação dos dois programas, entre outros aspectos, possibilitou: o aumento dos recursos federais para a Educação Superior Pública, que passaram de 9,5 bilhões de reais investidos em 2003, para 22,1 bilhões de reais investidos em 2010; a criação de 14 novas IFES; 126 novos campi universitários; mais que a duplicação do número de vagas disponíveis anualmente nas IFES - em 2003 eram disponibilizadas 109.200 vagas por ano nestas instituições e em 2010 o número de vagas disponíveis foi de 243.500. Dados disponíveis no sítio eletrônico www.balancodegoverno.presidencia.gov.br - em que está 
|96|

Política de reconhecimento das diferenças...

ampliação da estrutura da Educação Superior Pública e consequente ampliação do acesso a ela, teve impacto positivo sobre as comunidades acadêmicas para a adoção e implementação das ações afirmativas, como políticas também inovadoras de democratização do acesso e permanência nas IFES.

Uma ressalva a ser feita, dentre as iniciativas do Governo Federal entre 2003 e 2010 em sua relação com a adoção e implementação de ações afirmativas nas IFES, diz respeito ao Sistema de Seleção Unificada (SiSU). Proposto para início em 2010, mas ganhando força pela adesão das IFES para a seleção de ingressantes em seus cursos em 2011 o SiSU, executado pelo MEC, utiliza como avaliação para ingresso ao Ensino Superior o Exame Nacional do Ensino Médio (ENEM). Assim é uma política que tem a virtude de se apresentar como alternativa aos vestibulares isolados, executados habitualmente por grandes fundações - que mesmo por vezes vinculadas a estabelecimentos públicos de ensino, em sua maioria obedecem à racionalidade privada de obtenção principalmente do lucro ao aplicar suas avaliações. Mesmo prevendo em seu desenho a possibilidade do/a candidato/ a se inscrever para concorrer a vagas disponíveis nas instituições por formas de ação afirmativa, ao estabelecer, no entanto, certa homogeneização no processo de admissão para ingresso nos cursos de graduação das universidades que dele participam, o SiSU pode estar interferindo nos desenhos institucionais próprios, adotados pelas IFES, para suas políticas afirmativas para acesso aos cursos de graduação, de forma a não contribuir com sua organização enquanto políticas institucionais. ${ }^{28}$

o balanço oficial de governo do período 2003-2010 - consultado em 30 de setembro de 2011.

${ }^{28}$ O SiSU é adotado pelas instituições públicas que decidem a ele aderir Em 2011 participam do SiSU, segundo informações do MEC, 48 Instituições Públicas de Ensino Superior. Dados disponíveis no sítio eletrônico http://sisu.mec.gov.br/\#/principal.php - consultado em 30 de setembro de 2011. 
É possível afirmar que as medidas adotadas pelo governo Lula para a Educação Superior indicam fortes elementos de sinergia com a decisão de adoção e/ou o processo de implementação de ações afirmativas pelas IFES. Uma possível exceção parece ser o SiSU, apesar dos aspectos positivos desta medida ao se viabilizar como alternativa aos vestibulares isolados. Não é demasiado lembrar, entretanto, o aspecto bastante inicial da reflexão apresentada e que carece de aprofundamento analítico posterior, com estudos de caso e/ou comparativos sobre a implementação das ações afirmativas em IFES, na relação cotidiana estabelecida no plano da gestão das universidades entre estas políticas e as medidas tomadas pelo Governo Federal para a Educação Superior Pública.

\section{Considerações finais}

Impulsionadas pelas reivindicações e propostas do movimento negro, para enfrentar especificamente as desigualdades raciais no acesso da população negra ao Ensino Superior, verifica-se que a maior parte das experiências de ações afirmativas nas universidades públicas apresenta critérios étnicoraciais que contemplam a forma destas demandas iniciais notadamente apresentadas como reserva de vagas ou cotas exclusivamente para a negros/as para ingresso nos cursos de graduação -, mas combina ou soma também a estes outros critérios, que fazem as ações afirmativas atenderem um conjunto de outros grupos subalternos. ${ }^{29}$ Assim sendo, evidencia-se que a dinâmica do reconhecimento das diferenças étnico-raciais, desenvolvida nos espaços públicos e na institucionalidade das IFES, ao construir a legitimidade de políticas sensíveis à desigualdade racial a que está submetida a população negra, abre também caminho para problematizar outras formas de

29 FERES JÚNIOR, J. Op. Cit., p. 44. 
|98|

Política de reconhecimento das diferenças...

desigualdade e incluí-las como parte das políticas afirmativas. Ao contrário de construir "privilégios corporativos", como tenta argumentar José de Souza Martins, ${ }^{30}$ o que as experiências de ações afirmativas no Ensino Superior Público apontam é um processo dinâmico de ampliação do reconhecimento das diferentes expressões da subalternização, desta forma, também o reconhecimento das múltiplas formas em que se apresenta a desigualdade - seja esta por trajetória educacional, classe, raça, etnia, origem nacional, origem regional etc. ${ }^{31}$

Afetando uma das bases da reprodução da desigualdade, o acesso a Educação Superior, ${ }^{32}$ não me parece que uma nova

\footnotetext{
${ }^{30}$ Ver MARTINS, J. S. "A identidade contra a desigualdade: as identidades sociais dinâmicas". In CAVALCANTI, J.S.B., WEBER, S. \& DWYER, T. (orgs.) Desigualdade, Diferença e Reconhecimento. Porto Alegre, Tomo Editorial, 2009. p. 52.

${ }^{31}$ Neste sentido a experiência da Universidade Federal de São Carlos (UFSCar) parece-me exemplar. Tendo iniciado, a partir de demanda do movimento negro e de intelectuais acadêmicos negros/as e anti-racistas desta IFES, as discussões sobre o desenho institucional do que se tornaria, a partir de 2008, seu Programa de Ações Afirmativas (PAA), acabaram por construir uma política de acesso diferenciado que combinou critérios de trajetória educacional (reserva de vagas para egressos de escolas públicas), com critérios raciais (reserva de vagas para negros, ou seja, auto-declarados pretos e pardos) e étnicos (reserva de vagas para indígenas que se auto-identifiquem com algum dos grupos étnicos indígenas presentes no Brasil, mas também sejam assim reconhecidos por suas comunidades de origem). Entretanto, durante o processo de implementação deste PAA, foram sendo incorporadas outras metas ao programa, que hoje também mantêm acesso diferenciado para refugiados, além de fazer o acompanhamento acadêmico de estudantesconvênio PEC-G e também manter vínculo institucional com o curso de Pedagogia da Terra - graduação voltada exclusivamente a estudantes participantes de grupos em luta pela terra. Informações sobre o PAAUFSCar podem ser acessadas em www.acoesafirmativas.ufscar.br.

${ }^{32}$ Ver HASENBALG, C. \& SILVA, N. D. Origens e destinos: desigualdade social ao longo da vida. Rio de Janeiro: Topbooksed, 2003.
} 
política de reconhecimento das diferenças, tendo como um de seus mais significativos indicadores a expansão de ações afirmativas também sensíveis à desigualdade racial, esteja associada necessariamente ao regime neoliberal como define Guimarães. Pelo contrário, me parece uma evidência de que está em disputa, não só a volta da modernização conservadora, como argumenta Vianna, ou a continuidade do neoliberalismo - como em Oliveira, Coutinho ou Guimarães -, mas também a perspectiva de uma democracia emergente, que Evelina Dagnino sintetiza na noção do projeto democrático-participativo ${ }^{33}$. Este projeto, mesmo longe de se apresentar como hegemônico em nossa ordem social, não me parece "invisível", como parte destes analistas parece crer. Ao contrário, se tomamos como exemplo as mudanças na política de reconhecimento das diferenças étnico-raciais, parece-me que o período sob a presidência de Lula coloca a disputa por uma nova hegemonia, cujos contornos ainda estão por se estabelecer, de maneira bastante presente.

${ }^{33}$ DAGNINO, E. Op. Cit. 2004. 